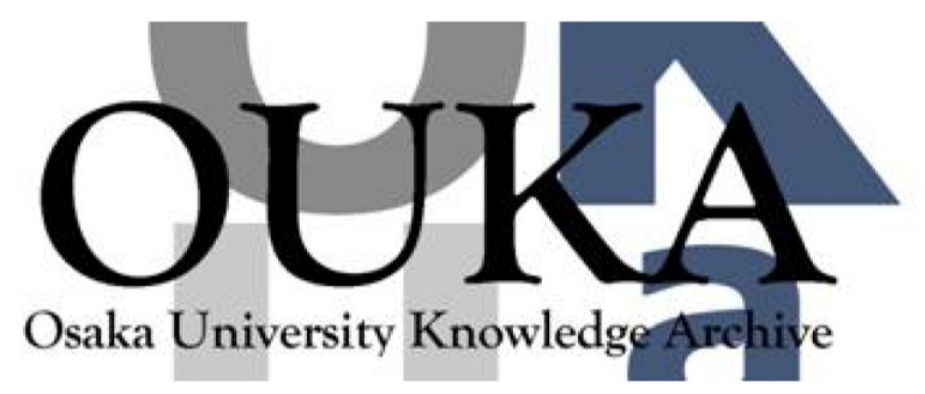

\begin{tabular}{|c|l|}
\hline Title & $\begin{array}{l}\text { 3-Nitrochromenes for Second Order Nonlinear } \\
\text { Optical Applications }\end{array}$ \\
\hline Author(s) & $\begin{array}{l}\text { Ono, Noboru; Sugi, Kiyoshi; Ogawa, Takuji et } \\
\text { al. }\end{array}$ \\
\hline Citation & $\begin{array}{l}\text { JOURNAL OF THE CHEMICAL SOCIETY-CHEMICAL } \\
\text { COMMUNICATIONS. 23 p. 1781-p. 1782 }\end{array}$ \\
\hline Issue Date & 1993-12-07 \\
\hline oaire:version & VoR \\
\hline URL & https://hdl. handle. net/11094/3015 \\
\hline rights & \\
\hline Note & \\
\hline
\end{tabular}

Osaka University Knowledge Archive : OUKA

https://ir. Library. osaka-u. ac. jp/

Osaka University 


\section{3-Nitrochromenes for Second Order Nonlinear Optical Applications}

\section{Noboru Ono,* a Kiyoshi Sugi, ${ }^{a}$ Takuji Ogawa a and Shinji Aramaki ${ }^{b}$}

a Department of Chemistry, Faculty of Science, Ehime University, Matsuyama 790, Japan

- Mitubishi Kasei General Research Center, Kamosidacho, Midoriku, Yokohama, 227, Japan

3-Nitrochromenes bearing various substitutents have been prepared by the reaction of substituted salicylaldehydes with nitrostyrenes; some of these compounds have been found to display efficient optical second harmonic generation.

Organic materials with second-order nonlinear optical properties have been the subject of intense investigation owing to their large nonlinearity and ultrafast response times. ${ }^{1}$ These materials have many potential applications in a variety of laser-related technologies such as telecommunication, optical computing, optical storage, and optical information processing. The design of these molecules rests on the combination of an electron donor, a $\pi$-conjugated electronic system, and an electron acceptor. Donor-acceptor substituted aromatic compounds have been extensively studied for second-order nonlinear materials. In this paper we report a new system for second harmonic generation (SHG); 3-nitrochromenes with appropriate substituents are potential candidates for future nonlinear optical applications.

3 -Nitrochromenes 2 were prepared in $70-80 \%$ yield by the reaction of substituted salicylaldehydes 1 with nitrostyrenes under basic conditions. ${ }^{2}$ Nitrostyrenes were prepared by the reaction of aromatic aldehydes with nitromethane. As this method affords 2 with a variety of substituents, the effect of the substituent on SHG efficiency can be investigated in a systematic way. 3-Nitrochromenes thus obtained are all yellow crystals with an absorption maximum at about $390 \mathrm{~nm}$.<smiles>[R7]c1cc([R7])c(O)c(C=O)c1</smiles>

Reagents and conditions: $\mathrm{i}, \mathrm{Et}_{3} \mathrm{~N}, \mathrm{CH}_{2} \mathrm{Cl}_{2}$, room temperature; ii, $\mathrm{Al}_{2} \mathrm{O}_{3}$ 
Table 1 Preparation of 3-nitrochromenes 2, and SHG efficiency of 2

\begin{tabular}{|c|c|c|c|c|c|c|}
\hline Entry & $\mathrm{R}^{1}$ & $\mathrm{R}^{2}$ & $\mathrm{Ar}$ & $\begin{array}{l}\text { Yield } \\
(\%)\end{array}$ & $\lambda_{\max } / \mathrm{nm}^{a}$ & $\begin{array}{l}\text { SHG } \\
\text { efficiency }\end{array}$ \\
\hline 1 & $\mathrm{H}$ & $\mathrm{H}$ & $\mathrm{Ph}$ & 84 & 392,319 & 0 \\
\hline 2 & $\mathrm{H}$ & $\mathrm{H}$ & $p-\mathrm{MeOC}_{6} \mathrm{H}_{4}$ & 80 & 390,318 & 0.013 \\
\hline 3 & $\mathrm{H}$ & $\mathrm{OMe}$ & $\mathrm{Ph}$ & 70 & 345 & 0 \\
\hline 4 & $\mathrm{H}$ & $\mathrm{OMe}$ & $p-\mathrm{MeOC}_{6} \mathrm{H}_{4}$ & 84 & 346 & 0 \\
\hline 5 & $\mathrm{Cl}$ & $\mathrm{H}$ & $\mathrm{Ph}$ & 68 & 399,314 & 0.091 \\
\hline 6 & $\mathrm{Cl}$ & $\mathrm{H}$ & $p-\mathrm{MeOC}_{6} \mathrm{H}_{4}$ & 80 & 396,312 & 62 \\
\hline 7 & $\mathrm{Cl}$ & $\mathrm{H}$ & 2-Thienyl & 73 & 393,312 & 43 \\
\hline 8 & $\mathrm{Cl}$ & $\mathrm{H}$ & $3,4-(\mathrm{MeO})_{2} \mathrm{C}_{6} \mathrm{H}_{3}$ & 78 & 395,312 & 0.013 \\
\hline
\end{tabular}

${ }^{a}$ In $\mathrm{CH}_{2} \mathrm{Cl}_{2} .{ }^{b}$ Measured by the powder method using a YAG laser $(1064 \mathrm{~nm})$. Values are relative to urea.

We investigated the SHG efficiencies of $\mathbf{2}$ by means of the powder technique. ${ }^{3}$ This is a convenient method for screening a large number of powdered materials for non-linear optical activities by observing the light emitted from the powdered materials on laser irradiation. The SHG efficiency was determined relative to a reference compound (urea). The results are summarized in Table 1 . Compounds in entries 2, 5, 6, 7 and 8 gave SHG effects, compounds in entries 6 and 7 displaying by far the most intense signals, much stronger than that of urea. They have an SHG efficiency 62 and 43 times that of urea, respectively. This value is remarkable among existing nonlinear optical materials based on nitroaromatic derivatives. ${ }^{1}$ The lack of SHG for compounds in entries 1,3 and 4 could be caused by bulk effects. The magnitude of the SHG signals obtained from the powder test is mainly governed by crystallographic factors. As shown in Table 1, a small change of substituents in $\mathbf{2}$ has a large effect on the SHG efficiency. The present results, albeit qualitative, indicate that fused heteroaromatic compounds such as $\mathbf{2}$ are good candidates for the design of new non-linear optical materials. ${ }^{4}$ More quantitative treatment is necessary to understand structural factors that govern intrinsic hyperpolarizability of 2 . Such work is now in progress.

The work described herein was supported by Nissan Science Foundation.

Received, 23rd July 1993; Com. 3/04373H

\section{References}

1 P. N. Prasad and D. J. Williams, Introduction to Nonlinear Optical Effective Molecules and Polymers, Wiley, 1991; Nonlinear Optical Properties of Organic Molecules and Crystals, ed. D. S. Chemla and J. Zyss, vol. 1 and 2, Academic Press, Orlando, 1987; Nonlinear Optical Properties of Organic and Polymeric Materials, ed. D. J. Williams, ACS Symp. Ser. 233, Washington DC, 1983; D. J. Williams, Angew. Chem., Int. Ed. Engl., 1984, 23, 690.

2 S. V. Rajender, K. Mirayam and W. K. Geroge, Synthesis, 1986, 486.

3 S. Kurtz and T. T. Perry, J. Appl. Phys., 1989, 39, 3978.

4 Fused heteroaromatic compounds for nonlinear optical materials: see M. M. Bader, T. Hamada and A. Kakuta, J. Am. Chem. Soc., 1992, 114, 6475; H. Nakazumi, S. Watanabe, K. Maeda and T. Kitao, Chem. Lett., 1990, 679. 